Provided for non-commercial research and education use. Not for reproduction, distribution or commercial use.

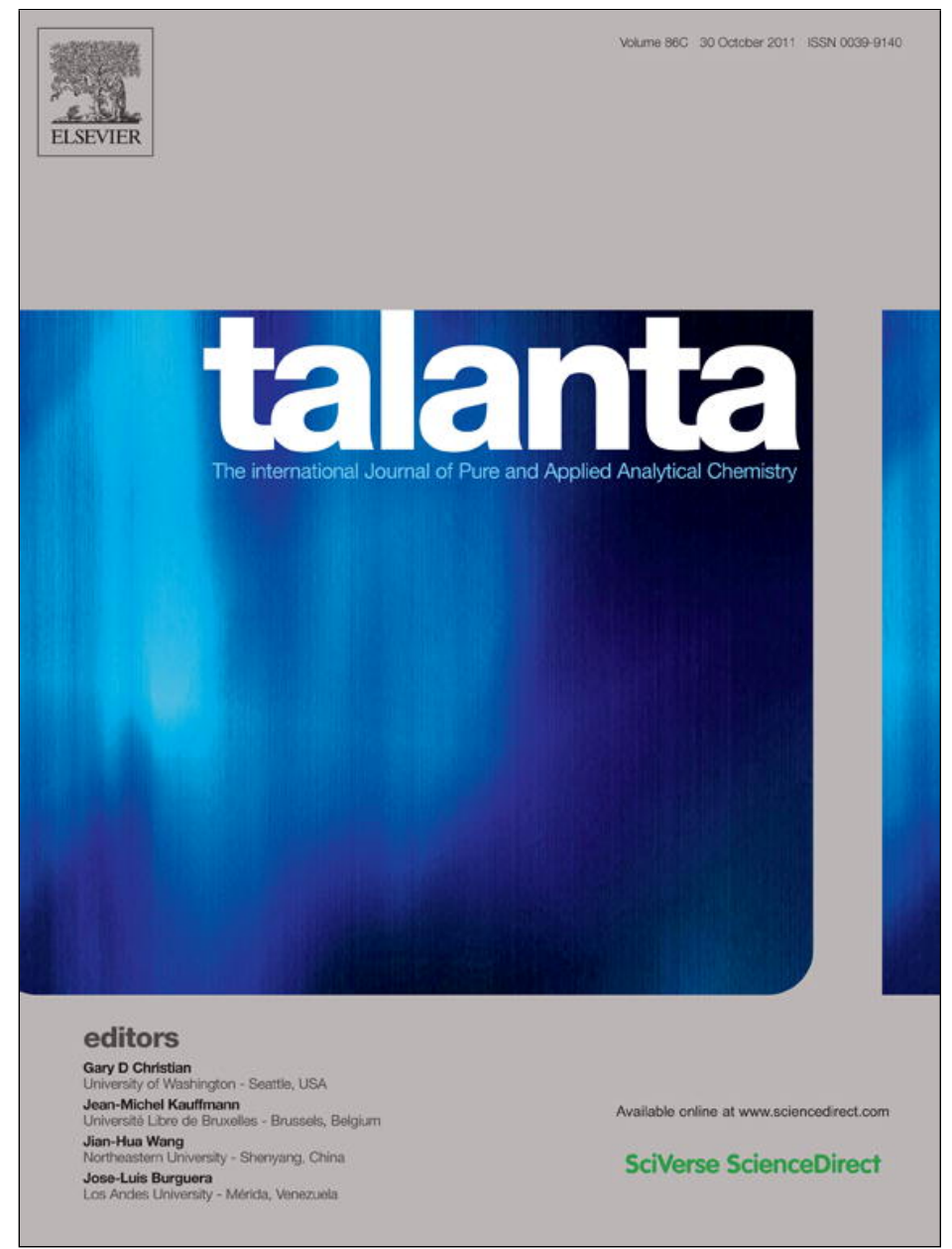

This article appeared in a journal published by Elsevier. The attached copy is furnished to the author for internal non-commercial research and education use, including for instruction at the authors institution and sharing with colleagues.

Other uses, including reproduction and distribution, or selling or licensing copies, or posting to personal, institutional or third party websites are prohibited.

In most cases authors are permitted to post their version of the article (e.g. in Word or Tex form) to their personal website or institutional repository. Authors requiring further information regarding Elsevier's archiving and manuscript policies are encouraged to visit:

http://www.elsevier.com/copyright 


\title{
A fast method using a new hydrophilic-lipophilic balanced sorbent in combination with ultra-high performance liquid chromatography for quantification of significant bioactive metabolites in wines
}

\author{
Catarina L. Silva ${ }^{a}$, Jorge Pereira ${ }^{a}$, Van G. Wouter ${ }^{a, b}$, Carme Giró ${ }^{a, c}$, José S. Câmara ${ }^{a, *}$ \\ a CQM - Centro de Química da Madeira, Centro de Ciências Exactas e da Engenharia da Universidade da Madeira, Campus Universitário da Penteada, $9000-390$ Funchal, Portugal \\ ${ }^{\mathrm{b}}$ Katholieke Hogeschool Kempen, Kleinhoefstraat 4, 2440 Geel, Belgium \\ ' Institut de l'Aigua, Universitat de Barcelona, Avinguda Diagonal, 684, 08034 Barcelona, Spain
}

\section{A R T I C L E I N F O}

\section{Article history:}

Received 8 June 2011

Received in revised form 2 August 2011

Accepted 6 August 2011

Available online 1 September 2011

\section{Keywords:}

Wines

Bioactive metabolites

Solid phase extraction

Ultra-high performance liquid

chromatography

\begin{abstract}
A B S T R A C T
This manuscript describes the development and validation of an ultra-fast, efficient, and high throughput analytical method based on ultra-high performance liquid chromatography (UHPLC) equipped with a photodiode array (PDA) detection system, for the simultaneous analysis of fifteen bioactive metabolites: gallic acid, protocatechuic acid, (-)-catechin, gentisic acid, (-)-epicatechin, syringic acid, $p$-coumaric acid, ferulic acid, $m$-coumaric acid, rutin, trans-resveratrol, myricetin, quercetin, cinnamic acid and kaempferol, in wines. A $50-\mathrm{mm}$ column packed with $1.7-\mu \mathrm{m}$ particles operating at elevated pressure (UHPLC strategy) was selected to attain ultra-fast analysis and highly efficient separations. In order to reduce the complexity of wine extract and improve the recovery efficiency, a reverse-phase solid-phase extraction (SPE) procedure using as sorbent a new macroporous copolymer made from a balanced ratio of two monomers, the lipophilic divinylbenzene and the hydrophilic N-vinylpyrrolidone (Oasis ${ }^{\mathrm{TM}}$ HLB), was performed prior to UHPLC-PDA analysis. The calibration curves of bioactive metabolites showed good linearity within the established range. Limits of detection (LOD) and quantification (LOQ) ranged from $0.006 \mu \mathrm{g} \mathrm{mL}^{-1}$ to $0.58 \mu \mathrm{g} \mathrm{mL}^{-1}$, and from $0.019 \mu \mathrm{g} \mathrm{mL}^{-1}$ to $1.94 \mu \mathrm{g} \mathrm{mL}^{-1}$, for gallic and gentisic acids, respectively. The average recoveries \pm SD for the three levels of concentration tested $(n=9)$ in red and white wines were, respectively, $89 \pm 3 \%$ and $90 \pm 2 \%$. The repeatability expressed as relative standard deviation (RSD) was below $10 \%$ for all the metabolites assayed. The validated method was then applied to red and white wines from different geographical origins (Azores, Canary and Madeira Islands). The most abundant component in the analysed red wines was (-)-epicatechin followed by (-)-catechin and rutin, whereas in white wines syringic and $p$-coumaric acids were found the major phenolic metabolites.

The method was completely validated, providing a sensitive analysis for bioactive phenolic metabolites detection and showing satisfactory data for all the parameters tested. Moreover, was revealed as an ultra-fast approach allowing the separation of the fifteen bioactive metabolites investigated with high resolution power within $5 \mathrm{~min}$.
\end{abstract}

(C) 2011 Elsevier B.V. All rights reserved.

\section{Introduction}

The molecules present in wines cover a large number of metabolites including primary (e.g., sugars, organic acids, amino acids) and secondary metabolites (e.g., polyphenols including flavonoids, anthocyanins, and other pigments). These compounds have a strong influence on the quality and character of the wine, and therefore are important not only for their characterization and differentiation, but also for fraud detection [1-6]. In recent years considerable attention is being paid to natural substances with

\footnotetext{
* Corresponding author. Tel.: +351 291705112; fax: +351 291705149

E-mail address: jsc@uma.pt (J.S. Câmara).
}

antioxidant activity, which play a crucial role in the prevention of cardiovascular, neurodegenerative and cancer diseases acting through different mechanisms, namely direct trapping of reactive oxygen species (ROS) and reactive nitrogen species (RNS, i.e. nitric oxide), inhibition of enzymes responsible for producing superoxide anions, chelation of transition metals involved in processes that originate radicals and prevention of the peroxidation process by reducing alkoxyl and peroxyl radicals. Grapes and grape-derived products such as red wine are an abundant source of antioxidants (phenolic compounds) and represent an important dietary component $[1,2]$. Their nature and content can vary significantly according to different intrinsic and extrinsic factors such as plant genetics and cultivar, soil composition and growing conditions, maturity state and post-harvest conditions, among others [5,6]. 
a

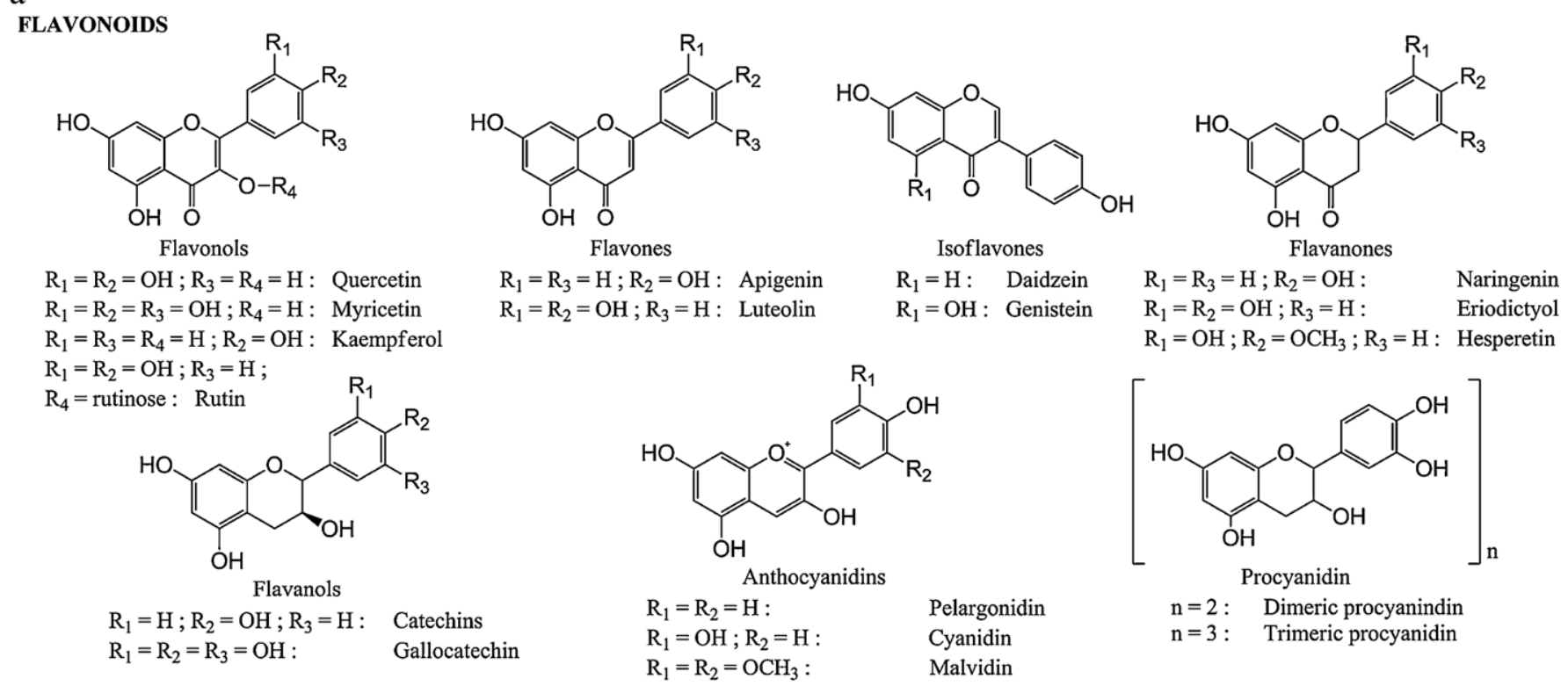

b

\section{NON-FLAVONOIDS}

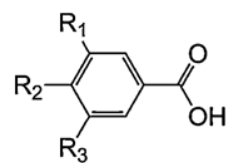

Benzoic acids
PHENOLIC ACIDS

$\mathrm{R}_{1}=\mathrm{R}_{2}=\mathrm{R}_{3}=\mathrm{OH}: \quad$ Gallic acid

$\mathrm{R}_{1}=\mathrm{R}_{2}=\mathrm{OH} ; \mathrm{R}_{3}=\mathrm{H}$ :Protocatechuic acid

$\mathrm{R}_{1}=\mathrm{R}_{3}=\mathrm{H}$;

$\mathrm{R}_{2}=\mathrm{OH}: p$-hydroxybenzoic acid

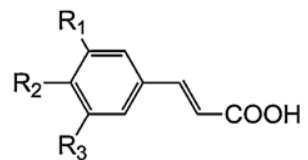

Hydroxycinnamic acids

p-coumaric aci

$\begin{array}{ll}\mathrm{R}_{1}=\mathrm{H} ; \mathrm{R}_{2}=\mathrm{R}_{3}=\mathrm{OH}: & \text { Caffeic acid } \\ \mathrm{R}_{1}=\mathrm{H} ; \mathrm{R}_{2}=\mathrm{OH} ; \mathrm{R}_{3}=\mathrm{OCH}_{3}: \text { Ferulic acid }\end{array}$<smiles>[R]c1cc([R2])cc(/C=C/c2cc([R3])c([R4])c([R5])c2)c1</smiles><smiles>COc1cc(CC(CO)C(CO)Cc2ccc(O)c(OC)c2)ccc1O</smiles>

$\mathrm{R}_{1}=\mathrm{R}_{2}=\mathrm{R}_{3}=\mathrm{R}_{4}=\mathrm{R}_{5}=\mathrm{H}$ : $\quad$ Stilbene

$\mathrm{R}_{1}=\mathrm{R}_{2}=\mathrm{R}_{4}=\mathrm{OH} ; \mathrm{R}_{3}=\mathrm{R}_{5}=\mathrm{H}$ : Resveratrol Secoisolariciresinol

$\mathrm{R}_{1}=\mathrm{R}_{2}=\mathrm{R}_{3}=\mathrm{R}_{4}=\mathrm{OH} ; \mathrm{R}_{5}=\mathrm{H}$ : Piceatannol

Fig. 1. Chemical structures of different classes of polyphenols.

Phenolic compounds, mainly polyphenols, are responsible for some of the organoleptic characteristics of the fruits, food and drinks [7], and act as potent antioxidants, reinforcing antioxidant system against ROS and RNS. In fact, several studies associate to polyphenols a wide range of biological effects, including antibacterial, anti-inflammatory, anti-allergic and antithrombotic activities [8]. Moreover, accumulating data from numerous epidemiological studies indicate that regular intake of polyphenol-rich beverages and foods such as red wine, tea, chocolate, fruit and vegetables lead to a reduction of vascular oxidative stress and consequent increase of endothelial function, thus improving cardiovascular protection [9]. The role of polyphenols in this protection as in vivo antioxidants is clearly strengthened by their ability to bind to LDL, preventing its oxidation and consequent atherosclerosis development $[9,10]$. These bioactive molecules can be categorized as flavonoids and nonflavonoids phenolic compounds. The first class includes flavonols, represented mainly by quercetin, kaempferol, and myricetin; flavones represented by apigenin and luteolin; flavan-3-ols, ranging from the simple monomers (+)-catechin and its isomer (-)-epicatechin to the oligomeric and polymeric proanthocyanidins; flavanones, isoflavones, and anthocyanidins. The nonflavonoids includes $\mathrm{C} 6-\mathrm{C} 1$ phenolic acids such as gallic, $p$ hydroxybenzoic, protocatechuic, vanillic, and syringic acids; C6-C3 hydroxycinammates: $p$-coumaric, caffeic, and ferulic acids (frequently accumulate as their respective tartrate esters, coutaric, caftaric, and fertaric acids) and their conjugated derivatives; and stilbenes $[3,11]$. The chemical structures of polyphenols are reported in Fig. 1.

Owing to the complex nature of the wine matrix, there is a consensus on that efficient sample preparation trace-level detection and identification are important aspects of analytical methods to determine polyphenols in wines.

The technique most frequently used for sample extraction or clean-up is liquid-liquid extraction (LLE). However, in some cases, such methodology is still not selective enough to comply with the needs of food safety and regulations. Nowadays SPE is becoming more popular because it require less organic solvent, is easy to implement, allow high sample throughputs and, in general, is used with good results. In this way, $\mathrm{C}_{18}$ cartridges have been widely used in polyphenolic compounds extraction, nevertheless they present some disadvantages, such as low recoveries for some polar compounds, namely hydroxybenzoic and hydroxycinnamic acids.

According to Perez-Magarino et al. [12] the use of polymer cartridge, mainly the HLB with $\mathrm{N}$-vinylpyrrolidone-divinylbenzene copolymer as sorbent seems to be a good alternative to replace $\mathrm{C}_{18}$ cartridges. These HLB cartridges present stronger retention and selectivity, enhanced capture of polar analytes and excellent wettability, maintaining high retention and capacity even if it runs dry after conditioning. They are stable in organic solvents and wide $\mathrm{pH}$ variations (0-14), allowing high and reproducible recoveries for acidic, basic and neutral compounds. 
Table 1

Recent HPLC and UHPLC methods dealing with the analysis of wine polyphenols.

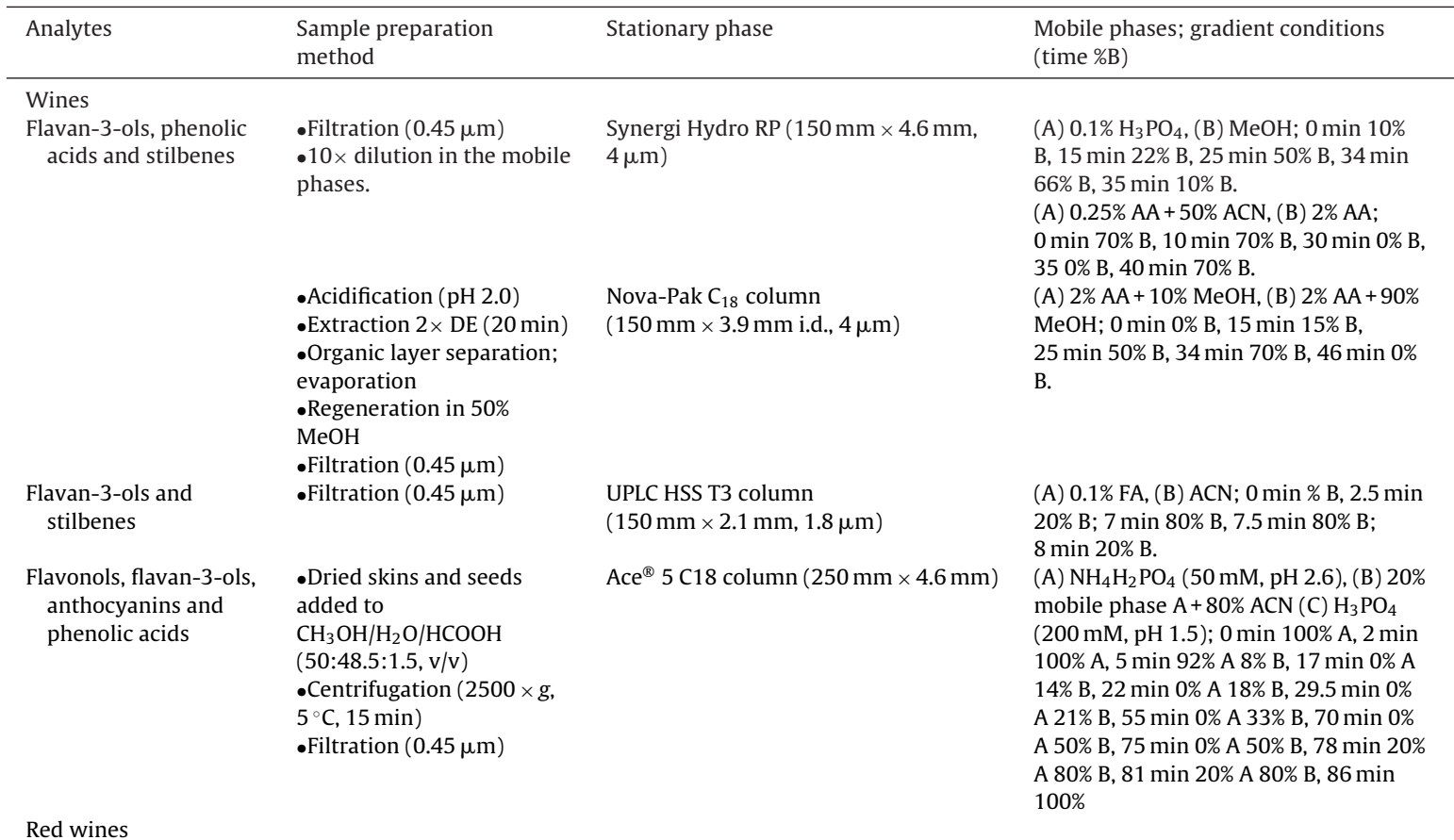

Flavan-3-ols, flavonols, •Freeze-drying and liquid flavanol dimmers phenolic acids and organic acids

Flavan-3-ols, flavonols phenolic acids and stilbenes

Flavan-3-ols, flavonols and phenolic acids

Flavanols, anthocyanins and phenolic acids

extraction

-Extract fractionation by

semipreparative

C18-RP-HPLC.

-Filtration $(0.45 \mu \mathrm{m})$

-Dilution 1:10 (10\%

$\mathrm{MeOH}+10 \mathrm{mM}$ ammonium

formate buffer $\mathrm{pH} 3.75$ ).

•Filtration $(0.45 \mu \mathrm{m})$

-Dealcoholization and acidification (concentrated

FA pH 2.0)
-Fractionation into

aqueous and organic

fractions using LLE and SPE

Flavonols and flavones •Filtration $(0.45 \mu \mathrm{m})$

Flavan-3-ols, flavonols, flavones, phenolic acids and others phenolics

White wines

Glutathione, catechin and caffeic acid

Phenolic acids

-Filtration $(0.45 \mu \mathrm{m})$ -Dilution to $90 \%$ with Milli-Q water.

-Centrifugation (14,000 rpm, $5 \mathrm{~min}$ ) -Derivatization with p-benzoquinone. -Infusion (dry leaves incubation in distilled water $10 \mathrm{~min}, 80^{\circ} \mathrm{C}$ )

-Filtration (3500 rpm, $5 \mathrm{~min}, 0.22 \mu \mathrm{m}$ )

Other wines (Brandies, fruit wines and model wine solutions)

Phenolic acids, $\quad$ Filtration $(0.22 \mu \mathrm{m}) \quad$ LiChrospher RP- $\mathrm{C}_{18}$ column aldehydes and furan

$(250 \mathrm{~mm} \times 4 \mathrm{~mm}$ i.d., $5 \mu \mathrm{m})$
BEH $\mathrm{C}_{18}$ column $(100 \mathrm{~mm} \times 2.1 \mathrm{~mm}$ i.d., $1.7 \mu \mathrm{m})$

HT C-18 reversed phase $(50 \mathrm{~mm} \times 2.1 \mathrm{~mm}, 1.8 \mu \mathrm{m})$

OmniSpher $\mathrm{C} 18$ column

$(250 \mathrm{~mm} \times 4.6 \mathrm{~mm})$; ChromSep guard column $(100 \mathrm{~mm} \times 3 \mathrm{~mm})$ $\mathrm{XTerra}^{\mathrm{TM}}$ MS $\mathrm{C} 18$ reverse phase column $(150 \mathrm{~mm} \times 2.1 \mathrm{~mm}, 3.5 \mu \mathrm{m})$; XTerra $^{\mathrm{TM}}$ MS C18 guard column $(10 \mathrm{~mm} \times 2.1 \mathrm{~mm}, 3.5 \mu \mathrm{m})$

LiChrospher 100RP-18e column $(250 \mathrm{~mm} \times 4.0 \mathrm{~mm}$ i.d., $5 \mu \mathrm{m})$; RP-18 $(10 \mathrm{~mm} \times 4.0 \mathrm{~mm})$ guard column

Kinetex C18 column $(100 \mathrm{~mm} \times 4.6 \mathrm{~mm}$ i.d., $2.6 \mu \mathrm{m})$

BEH C $_{18}$ column $(100 \mathrm{~mm} \times 1.7 \mathrm{~mm}$, $1.7 \mu \mathrm{m})$

$\mathrm{BEH}_{8}$ reversed phase colum $(150 \mathrm{~mm} \times 2.1 \mathrm{~mm}, 1.7 \mu \mathrm{m})$
A) $5 \% \mathrm{FA}$, (B) ACN; 0 min $10 \% \mathrm{~B}, 12 \mathrm{~min}$ $30 \% \mathrm{~B} ; 12.5$ min $50 \%, 13.5$ min $100 \% \mathrm{~B}$; 13.6 min $10 \% \mathrm{~B}$.

(A) $0.1 \% \mathrm{FA}+1 \% \mathrm{ACN}$, (B) $0.1 \% \mathrm{FA}+99 \%$ $\mathrm{ACN} ; 0$ min $2 \% \mathrm{~B}, 1.5 \mathrm{~min} 2 \% \mathrm{~B}$,

$11.25 \mathrm{~min} 45 \% \mathrm{~B}, 12.75 \mathrm{~min} 70 \% \mathrm{~B}$

$12.82 \mathrm{~min} 2 \% \mathrm{~B}$

(A) $0.1 \% \mathrm{H}_{3} \mathrm{PO}_{4}$, (B) $\mathrm{MeOH}$; 0 min $55 \%$

B, 30 min $80 \%$ B, 33 min $80 \%$ B, 35 min $5 \% \mathrm{~B}$.

Aqueous (anthocyanin) fraction:

(A) $2 \% \mathrm{FA}+2 \% \mathrm{ACN}$, (B) $2 \% \mathrm{FA}+80 \%$

ACN; 0 min $5 \%$ B, 11 min $15 \%$ B, 26 min

$30 \%$ B, 46 min $60 \%$ B, 69 min $80 \%$ B,

94 min 5\% B, 124 min 55 B.

Organic (non-anthocyanin) fraction

(A) $0.1 \% \mathrm{FA}+2 \% \mathrm{ACN}$, (B) $0.1 \% \mathrm{FA}+80 \%$

ACN; 0 min $5 \%$ B, 30 min $25 \%$ B, 35 min $30 \%$ B, 40 min $55 \%$ B, 45 min $55 \%$ B,

50 min $80 \%$ B, 85 min $5 \%$ B, 90 min $5 \%$ B.

(A) $19 \% \mathrm{ACN}+5 \% \mathrm{MeOH}+1 \% \mathrm{THF}(\mathrm{pH}$

3.0), (B) $55 \% \mathrm{ACN}+15 \% \mathrm{MeOH}(\mathrm{pH} 3.0)$;

0 min $2 \%$ B, 15 min $2 \%$ B, 28 min $28 \%$ B,

40 min 36\% B, 44 min 36\% B, 45 min

$80 \%$ B, 52 min $80 \%$ B.

(A) $0.1 \% \mathrm{FA}$, (B) ACN; 0 min $5 \% \mathrm{~B}, 4 \mathrm{~min}$

$5 \% \mathrm{~B}, 10 \mathrm{~min} 23 \% \mathrm{~B}, 15 \mathrm{~min} 23 \% \mathrm{~B}$,

19 min 50\% B, 20 min 95\% B.

(A) $0.05 \% \mathrm{TFA}$, (B) $\mathrm{MeOH} ; 0$ min $10 \% \mathrm{~B}$; 5 min $17 \%$ B; 7.5 min $30 \%$ B; 8.5 min $35 \% \mathrm{~B} ; 8.8 \mathrm{~min} 100 \% \mathrm{~B}$; $9.3 \mathrm{~min} 10 \% \mathrm{~B}$; $11 \mathrm{~min} 10 \% \mathrm{~B}$.

(A) $7.5 \mathrm{mM} \mathrm{FA}$, (B) ACN; 0 min $5 \% \mathrm{~B}, 5 \%$ B $0.8 \mathrm{~min}, 1.2 \mathrm{~min} 10 \% \mathrm{~B}, 1.9 \mathrm{~min} 10 \% \mathrm{~B}$, 2.4 min $15 \%$ B, 3.7 min $15 \%$ B, 4 min $21 \%$ B, 5.2 min $21 \%$ B, 5.7 min $27 \%$ B, 8 min $50 \%$ B, 9 min $100 \%$ B, 9.5 min $5 \%$ B.

A) $2 \% \mathrm{AA}+5 \% \mathrm{MeOH}$ (B) $2 \% \mathrm{AA}+90 \%$ $\mathrm{MeOH} ; 0$ min $0 \% \mathrm{~B}, 20 \mathrm{~min} 10 \% \mathrm{~B}$,

HPLC-PDA

UPLC-MS

C-MS/MS

HPLC-PDA

HPLC-DAD-MS

Detection Ref.
method

HPLC-UV/VIS

HPLC-MS/MS

RP-HPLC-DAD

UPLC-PDA

HPLC-DAD-FD $60 \min 75 \% \mathrm{~B}$. 
Table 1 (Continued)

\begin{tabular}{|c|c|c|c|c|c|}
\hline Analytes & $\begin{array}{l}\text { Sample preparation } \\
\text { method }\end{array}$ & Stationary phase & $\begin{array}{l}\text { Mobile phases; gradient conditions } \\
\text { (time \%B) }\end{array}$ & $\begin{array}{l}\text { Detection } \\
\text { method }\end{array}$ & Ref. \\
\hline $\begin{array}{l}\text { Anthocyanins and } \\
\text { hydroxycinnamic } \\
\text { acids }\end{array}$ & $\begin{array}{l}\text { - Reference solutions } \\
\text { prepared in a wine-like } \\
\text { medium (tartaric acid in } \\
\text { 12\% EtOH acidified to pH } \\
3.5 \text { ) }\end{array}$ & $\begin{array}{l}\text { UPLC BEH } C_{18} \text { column } \\
(100 \mathrm{~mm} \times 2.1 \mathrm{~mm} \text { i.d., } 1.7 \mu \mathrm{m}) \\
\text { BEH } C_{18} \text { column }(50 \mathrm{~mm} \times 2.1 \mathrm{~mm} \text { i.d., } \\
1.7 \mu \mathrm{m})\end{array}$ & 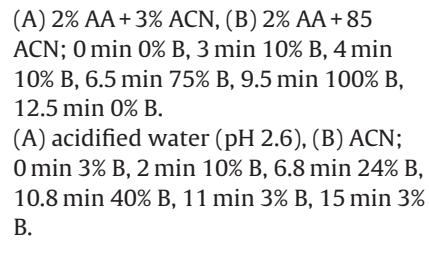 & $\begin{array}{l}\text { UPLC/ESI-TOF } \\
\text { MS }\end{array}$ & [13] \\
\hline
\end{tabular}

Abbreviations: PDA, photodiode array detection; DAD, diode array detection; DAD-ESI-MS, diode array detection and electrospray ionization mass spectrometry; DAD-FDED, diode array, fluorescence and electrochemical detectors; FD, fluorescence detector; LLE, liquid-liquid extraction; SPE, solid-phase extraction; SS-LLE, solid-supported liquid-liquid extraction; AA, acetic acid; ACN, acetonitrile; DE, diethyl ether; EA, ethyl ether; EtOH, ethanol; FA, formic acid; MeOH, methanol.

Liquid chromatographic (LC) methodologies represent, to date, the most widely used approach to phenolic analysis. Several methods for the detection and quantification of phenolic compounds in wines and other matrices, using this approach, have already been developed (Table 1). However, in some of the reported analytical methods the polyphenols separation require 40,50 or even $60 \mathrm{~min}$ of run analysis time per sample [14-18].

As an alternative, an ultra-fast UHPLC method appears recently to overcome some of the LC drawbacks retaining the principles of LC while offering some clear benefits in terms of analysis time, resolving power, solvent consumption and, to a lesser extent, sensitivity $[25,13]$. Up to now, only a few applications using UHPLC have been reported for the analysis of polyphenols (Table 1 ). Spacil et al. [14] compared a conventional HPLC system and a UHPLC system, equipped with columns containing similar stationary phases, in the analysis of wine and tea samples. While both analytical methods gave good results, the UHPLC system appeared to be superior. UHPLC methods are not only faster, more sensitive and more efficient, but are also more reliable and ecological [14,29].

Hence, the current research study is dedicated towards the development and validation of an ultra-fast, efficient and high throughput UHPLC-PDA method using a $50-\mathrm{mm}$ column (Acquity BEH RP18) packed with $1.7-\mu \mathrm{m}$ particles, for the separation and quantification of a wide range of bioactive polyphenols in wines. In order to reduce the complexity of wine extract and improve the recovery efficiency, a reverse-phase SPE procedure using as sorbent a new copolymer made from a balanced ratio of two monomers, the lipophilic divinylbenzene and the hydrophilic $N$-vinylpyrrolidone, was performed prior to UHPLC-PDA analysis. This method presents many advantages that include high resolution, speed, an exceptionally small sample volume and short running time for the separation. It was applied in red and white wines from different regions to characterize the phenolics with an efficient separation. Nevertheless, the method can be applied in several other applications such as plant extracts and dietary supplements.

\section{Materials and methods}

\subsection{Chemicals and standards}

For the UHPLC-PDA experiments, HPLC-gradient grade methanol (99.9\% purity) was obtained from Sigma-Aldrich (St. Louis, MO, USA). Ethanol and formic acid, both of HPLCgradient grade, were provided by Panreac Quimica SA (Barcelona, Spain) and ethyl acetate from Lab-Scan (Dublin, Ireland). The eluents were previously filtered with $0.22 \mu \mathrm{m}$ membrane filters (Millipore, Milford, MA, USA). The SPE cartridges used, Oasis ${ }^{\mathrm{TM}}$ HLB sorbent $(30 \mathrm{mg}$ ) from Waters was provided by Via Athena (Lisbon, Portugal). Finally, ultra-pure water was prepared from a
Milli-Q water purification system (Millipore, Bedford, MA, USA), Polyphenols standards gallic acid, gentisic acid, (-)-epicatechin, $m$-coumaric acid, cinnamic acid, $p$-coumaric acid, rutin, ferrulic acid and kaempferol, were supplied by Fluka Biochemica AG (Buchs, Switzerland), protocatechuic acid, (-)-catechin, syringic acid and trans-resveratrol, by Sigma-Aldrich (St. Louis, MO, USA), myricetin was acquired from Acros Organics (Geel, Belgium) and quercetin from Riedel-de-Haën (Seelze, Germany). The purity of all polyphenolic standards was greater than $95 \%$.

Individual stock solutions of all bioactive metabolites tested were prepared in pure methanol at concentrations of $1000 \mathrm{mg} \mathrm{L}^{-1}$, aliquoted in $4 \mathrm{~mL}$ vials, and stored at $-20^{\circ} \mathrm{C}$. Working standard solutions at various concentrations were prepared daily from the individual stock solutions in the mobile phase used at initial step of gradient elution (water at $0.1 \%$ formic acid with a $20 \%$ of methanol solution). These standards were used to spike the wines in order to perform the assays for method validation. The chemical structures of the investigated bioactive metabolites are reported in Fig. 1. Calibration standards were prepared fresh on the day of the analysis by diluting the appropriate working solutions with initial mobile phase solution. The ranges of concentrations were selected in function of sensitivity of the UHPLC-PDA towards each bioactive metabolite. Physical-chemical characteristics affect the analytical signal and for some compounds higher concentrations had to be used in order to detected the compound.

\subsection{Samples}

The methodology was applied to nine representative commercial table wines available from different regions, Madeira (TT, PT, LB, EB, SB, RBB), Azores (TLT) and Canary Islands (VT, VGB) which were produced according to standard procedures and defined varietal composition.

\subsection{Bioactive metabolites extraction procedure}

The polyphenols extraction procedure was based on reversephase SPE using Oasis ${ }^{\mathrm{TM}}$ HLB extraction cartridges. Briefly, $1 \mathrm{cc}$ $(30 \mathrm{mg})$ Oasis ${ }^{\mathrm{TM}}$ HLB extraction cartridges were conditioned with $1 \mathrm{~mL}$ of ethyl acetate and methanol and equilibrated with $1 \mathrm{~mL}$ of water. An aliquot of sample $(900 \mu \mathrm{L})$, previously acidified to $\mathrm{pH}$ 2.7 with acetic acid 30\%, was passed through the SPE cartridges at around $1.5 \mathrm{~mL} \mathrm{~min}^{-1}$ using an extraction unit (Alltech, SGE). The cartridges were washed with a solution of methanol $5 \%$ and subsequently the polyphenols were eluted with $500 \mu \mathrm{L}$ methanol, $1000 \mu \mathrm{L}$ ethyl acetate and finally $500 \mu \mathrm{L}$ methanol. The extracts were evaporated to dryness using a nitrogen stream. The dried residue was redissolved in $1000 \mu \mathrm{L}$ of initial mobile phase (water at $0.1 \%$ formic acid with a $20 \%$ of methanol solution), homogenized 
in a vortex agitator and filtered through a $0.22 \mu \mathrm{m}$ membrane filters before injection into UHPLC-PDA system. All extractions were carried out in triplicate, and each extract was injected three times.

\subsection{UHPLC-PDA analysis and operating conditions}

The analysis of bioactive metabolites were carried out on a Waters Ultra Performance Liquid Chromatographic Acquity system (UPLC, Acquity H-Class) (Milford, MA, USA) combined with a Waters Acquity quaternary solvent manager (QSM), an Acquity sample manager (SM), a column heater, a 2996 PDA detector, and a degassing system. The whole configuration was driven by Empower software v2.0 from Waters Corporation. Optimum separation was achieved with a binary mobile phase which consisted of (A) water at $0.1 \%$ formic acid, and (B) methanol, with a constant flow rate of $250 \mu \mathrm{Lmin}^{-1}$, giving a maximum back pressure of $6.000 \mathrm{psi}$, which is within the capabilities of the UHPLC. $2 \mu \mathrm{L}$ of extracts were injected into the Waters Acquity UPLC system, equipped with an Acquity UPLC ${ }^{\mathrm{TM}}$ bridged ethylene hybrid $\mathrm{BEH} \mathrm{C}_{18}$ analytical column $(1.7 \mu \mathrm{m}$ particle size, $2.1 \mathrm{~mm} \times 500 \mathrm{~mm})$ and protected with an Acquity UPLC ${ }^{\mathrm{TM}}$ BEH $\mathrm{C}_{18}$ Van Guard ${ }^{\mathrm{TM}}$ Pre-column $(1.7 \mu \mathrm{m}$, $2.1 \mathrm{~mm} \times 5 \mathrm{~mm}$ ) (Waters, Milford, MA, USA); column temperature was thermostated at $40^{\circ} \mathrm{C}$ and the samples were kept at $4{ }^{\circ} \mathrm{C}$ in the sample manager. The $5 \mathrm{~min}$ gradient was as follows: $0 \mathrm{~min}, 80 \% \mathrm{~A}$, $0.25 \mathrm{~min}, 70 \% \mathrm{~A}, 0.5 \mathrm{~min}, 68 \% \mathrm{~A}, 4 \mathrm{~min}, 20 \% \mathrm{~A}$, and $5 \mathrm{~min}, 80 \% \mathrm{~A}$, followed by a re-equilibration time of $3 \mathrm{~min}$, for bringing the column to the initial conditions after gradient analysis, given a total run time of $8 \mathrm{~min}$. All solvents and samples were filtered through $0.22 \mu \mathrm{m}$ membrane filters from Millipore (Millipore, Milford, MA, USA), before use. For quantification purposes the PDA detection was conducted by using four distinct channels that were set to the maximum absorbance wavelength of each polyphenol, 210, 270, 307 , and $360 \mathrm{~nm}$, as indicated in Table 3 . They were identified by comparing the retention time and spectral characteristics of their peaks with those of standards and they were quantified using the standards of each one.
Table 2

Concentration levels used in $\mathrm{SPE} \mathrm{Oasis}^{\circledR}{ }^{\mathrm{HLB}}$ validation studies.

\begin{tabular}{llcc}
\hline \multirow{2}{*}{ Metabolites } & \multicolumn{2}{l}{ Concentration level $\left(\mu \mathrm{g} \mathrm{mL}^{-1}\right)$} \\
\cline { 2 - 4 } & Low & Medium & High \\
\cline { 2 - 4 } & $(\mathrm{LL})$ & $(\mathrm{ML})$ & $(\mathrm{HL})$ \\
\hline Gallic acid & 0.5 & 5.0 & 10.0 \\
Protocatechuic acid & 2.0 & 12.0 & 30.0 \\
(-)-Catechin & 2.0 & 15.0 & 45.0 \\
Gentisic acid & 4.0 & 16.0 & 40.0 \\
(-)-Epicatechin & 5.0 & 20.0 & 60.0 \\
Syringic acid & 1.5 & 5.0 & 16.0 \\
p-Coumaric acid & 2.0 & 20.0 & 80.0 \\
Ferulic acid & 1.0 & 3.0 & 8.0 \\
$m$-Coumaric acid & 2.0 & 10.0 & 30.0 \\
Rutin & 3.0 & 15.0 & 32.0 \\
Trans-resveratrol & 2.0 & 15.0 & 60.0 \\
Myricetin & 3.5 & 20.0 & 60.0 \\
Quercetin & 2.0 & 10.0 & 30.0 \\
Cinnamic acid & 3.0 & 10.0 & 30.0 \\
Kaempferol & 2.0 & 15.0 & 40.0 \\
\hline
\end{tabular}

\subsection{Method validation}

Retention times were previously determined using individual standards. The method was validated in terms of selectivity, linearity, limits of detection (LOD) and quantification (LOQ), interand intra-day precisions, accuracy and extraction efficiency. The accuracy and precision studies were carried out by spiking red (PT) and white (LB) wines at three different concentration levels, corresponding to the low level (LL), medium level (ML) and highest point (HL) of calibration curve (Table 2 ).

The selectivity of the method was assessed by the absence of interfering peaks at the elution times of the bioactive metabolites. The linearity of the analytical method was evaluated building three calibration curves (the areas obtained were plotted against the corresponding standard concentrations) for each bioactive metabolite using standards, prepared in water at $0.1 \%$ formic acid with a $20 \%$ of methanol solution from individual stock solutions, at 7 different concentrations levels, including the zero point, run at different

Table 3

Validation process data showing the concentration range inside which the linearity was tested, retention times (RT), and results of regression for total area versus concentration and analytical performance for the bioactive metabolites (polyphenols) determined by SPE Oasis $^{\circledR}{ }_{\text {HLB }} /$ UPLC-PDA.

\begin{tabular}{|c|c|c|c|c|c|c|c|c|}
\hline \multirow[t]{2}{*}{ Peak number } & \multirow[t]{2}{*}{$\mathrm{RT}(\min )$} & \multirow[t]{2}{*}{ Bioactive metabolites } & \multirow[t]{2}{*}{$\lambda_{\max }{ }^{b}(n m)$} & \multicolumn{5}{|l|}{ Analytical performance } \\
\hline & & & & Conc. range $\left(\mu \mathrm{g} \mathrm{mL}^{-1}\right)$ & $y^{\mathrm{c}}$ & $R^{\mathrm{d}}$ & $\begin{array}{l}\text { LOD } \\
\left(\mu \mathrm{g} \mathrm{mL}^{-1}\right)^{\mathrm{e}}\end{array}$ & $\begin{array}{l}\text { LOQ } \\
\left(\mu \mathrm{g} \mathrm{mL}^{-1}\right)^{\mathrm{e}}\end{array}$ \\
\hline 1 & 0.664 & Gallic acid & 270 & $0.01-10.00$ & $8.98 E+07 x-7.82 E+03^{f}$ & 0.995 & 0.006 & 0.019 \\
\hline 2 & 1.032 & Protocatechuic acid & 270 & $0.10-30.00$ & $1.85 E+07 x-1.53 E+04$ & 0.985 & 0.008 & 0.026 \\
\hline 3 & 1.234 & (-)-Catechin & 210 & $2.50-45.00$ & $7.67 E+07 x+2.09 E+03$ & 0.983 & 0.089 & 0.297 \\
\hline 4 & 1.595 & Gentisic acid & 307 & $2.00-40.00$ & $2.06 E+06 x+1.58 E+03$ & 0.996 & 0.581 & 1.938 \\
\hline 5 & 2.044 & (-)-Epicatechin & 270 & $1.00-60.00$ & $9.52 E+05 x+7.03 E+02$ & 0.994 & 0.180 & 0.599 \\
\hline 6 & 2.210 & Syringic acid & 270 & $0.25-16.00$ & $5.90 E+06 x+4.18 E+03$ & 0.989 & 0.008 & 0.026 \\
\hline 7 & 2.615 & p-Coumaric acid & 307 & $0.05-80.00$ & $6.07 E+06 x+1.19 E+03$ & 0.997 & 0.011 & 0.035 \\
\hline 8 & 2.791 & Ferulic acid & 307 & $0.25-8.00$ & $122 E+07 x+4.46 E+03$ & 0.989 & 0.014 & 0.047 \\
\hline 9 & 2.946 & $m$-Coumaric acid & 315 & $0.25-30.00$ & $1.65 E+07 x+1.42 E+03$ & 0.994 & 0.076 & 0.255 \\
\hline 10 & 3.029 & Rutin & 360 & $1.00-32.00$ & $1.02 E+07 x+3.18 E+03$ & 0.998 & 0.011 & 0.038 \\
\hline 11 & 3.187 & Trans-resveratrol & 307 & $0.80-60.00$ & $3.52 E+06 x-5.57 E+03$ & 0.989 & 0.032 & 0.108 \\
\hline 12 & 3.393 & Myricetin & 360 & $2.50-60.00$ & $3.64 E+06 x-1.40 E+04$ & 0.995 & 0.038 & 0.128 \\
\hline 13 & 3.891 & Quercetin & 360 & $1.00-30.00$ & $6.14 E+06 x-1.31 E+04$ & 0.982 & 0.010 & 0.032 \\
\hline 14 & 4.108 & Cinnamic acid & 270 & $0.05-30.00$ & $2.27 E+07 x+2.70 E+03$ & 0.999 & 0.013 & 0.044 \\
\hline 15 & 4.388 & Kaempferol & 360 & $0.40-40.00$ & $1.09 E+06 x+5.56 E+03$ & 0.987 & 0.059 & 0.198 \\
\hline
\end{tabular}

RT: retention time $(\min )$

b $\lambda_{\max }$ : maximum absorbance wavelength.

$y$ : represents the peak area of bioactive phenolics.

d $R$ : correlation coefficient.

e LOD: limit of detection, the lowest analyte concentration that produces a response detectable above the noise level of the system - $\left(a+3 S_{a}\right) / b$, and LOQ, quantification limit, the lowest level of analyte that can be accurately and precisely measured $-\left(a+10 S_{a}\right) / b$.

${ }^{\mathrm{f}}$ Represents the concentration of bioactive phenolics in micrograms/milliliter. 
days. The zero point (extraction solvent) enables to verify that none of the compounds showed residual level or background signal. Each level of concentration was prepared in triplicate and injected three times, so there were a total of nine replicates.

Method sensitivity was assessed by determining the LOD (the lowest analyte concentration that produces a response detectable above the noise level of the system) and LOQ (the lowest level of analyte that can be accurately and precisely measured) for each compound. LOD and LOQ were calculated with the data generated in the linearity studies, being LOD defined as $\left(a+3 S_{a}\right) / b$ and LOQ as $\left(a+10 S_{a}\right) / b$, where " $a$ " represents origin ordinate, " $S_{a}$ " the origin ordinate variance and " $b$ " the slope. These parameters were calculated for each analyte from the standard solutions used to obtain the corresponding calibration curves, using the UHPLC developed method. For method precision, PT red wine and LB white wine, spiked at three different concentration levels (LL, ML and HL, see Table 2) of each polyphenol and treated by SPE ${ }_{\text {Oasis HLB }}$ were measured in seven replicates $(n=7)$ in the same day to obtain repeatability (intra-day precision), and three times over four different days to obtain inter-day precision (intermediate precision - IP). Both precision measures were expressed as \% RSD which describes the closeness of agreement between series of measurements.

In order to check the accuracy of the proposed method a recovery study was carried out by spiking a red wine (PT) and a white wine (LB), at three concentration levels (Table 2) in triplicate. The mixtures were subjected to the SPE $\mathrm{OasisHLB}_{\text {pro- }}$ cedure described in Section 2.3. The PT and LB wines phenolics concentration was previously determined, and the recovery values were calculated according to the following formula: Accuracy $=100 \times\left([\text { analyte }]_{\text {after spiking }}-[\text { analyte }]_{\text {before spiking }}\right) /[$ analyte added]; where [analyte] $]_{\text {after spiking }}$ is the analyte concentration in spiked wine; [analyte] before spiking is the analyte concentration in unspiked wine, and [analyte added] is the nominal concentration of the analyte added to wine. Extraction efficiency (EE) was determined by replicate analysis $(n=3)$ of bioactive phenolics standard solutions at medium level of concentration (ML) and processed as described above ( $\left.A_{S S-S P E}\right)$; a second solution with the same concentration was analysed but not submitted to $\mathrm{SPE}_{\text {Oasis } \mathrm{HLB}}$ $\left(A_{\mathrm{SS}}\right)$. The obtained peak area ratios were compared, and extraction efficiency was thus calculated: $\% E E=\left(A_{\mathrm{SS}-\mathrm{SPE}} / A_{\mathrm{SS}}\right) \times 100$.

\section{Results and discussion}

There is a variety of polyphenol compounds present in wines which has been demonstrated that possess rather potent antioxidant properties and a significant degree of bioavailability, resulting in beneficial health effects. For this reason it is important to develop efficient analytical methods able to assess these bioactive metabolites. In this work, the UHPLC method developed for the quantification of bioactive phenolics in wines extracts was found to be capable of giving a faster analysis with good resolution than that achieved with conventional HPLC.

\subsection{Method development and validation}

The most abundant bioactive metabolites often reported to be present in wine composition, such as gallic acid, (-)-catechin and (-)-epicatechin, as well others, like quercetin, that are not so abundant, but have a high bioactive potential against several diseases [30], were chosen to be analysed in this work. The wavelength that correspond to the maximum absorbance in the UV region was determined for each one of the polyphenols analysed (Table 3).

The method was validated by determining the selectivity, the linearity, the limits of detection (LOD) and quantification (LOQ), the inter- and intra-day precisions (expressed as \%RSD), the extraction efficiency and the accuracy at different levels of fortification. The spiking levels used for the accuracy and precision studies are summarized in Table 2.

Selectivity was assessed by the absence of interference in the same chromatographic windows as examined in a solution of standards of bioactive phenolics and analysis of "blank matrices" (extraction solvent). No interfering peaks were observed in the blank chromatograms (Fig. 2a) at the quantification wavelengths $(210,270,307,315$ and $360 \mathrm{~nm})$.

Method linearity was evaluated for each one of the 15 bioactive metabolites using standard solutions in order to demonstrate that concentration is linearly dependent on detector response, while other parameters influencing method precision and accuracy were determined using spiked real wines treated before or after SPE procedure. To determine the linearity of the method, calibration plots of the analyte peak area versus nominal standard concentrations using replicates $(n=3)$ at seven levels of concentration (Table 3) were constructed. These concentration levels covered the concentration ranges expected for the bioactive metabolites found in wines. Table 3 summarizes the validation process data showing the concentration range inside which the linearity was tested for each analyte, the slope, the origin ordinate, the correlation coefficients, and the limits of detection and quantification for the target metabolites.

As it can be seen through correlation coefficients, the linearity was satisfactory when using $\mathrm{SPE}_{\text {Oasis HLB }}$ method, with $R$-values above 0.991 for all bioactive metabolites (Table 3 ). The lowest value of $R$ was obtained for both quercetin and protocatechuic acid $(R>0.991)$ and the highest value for cinnamic acid $(R=0.999)$. The slope of the regression model depends on the extraction efficiency and on the detector response for each compound. Gallic acid, cinnamic acid, and protocatechuic acids, showed the highest slope values with $\mathrm{SPE}_{\text {Oasis HLB }}$ /UPLC-PDA methodology, while (-)-epicatechin obtained the lowest (Table 3).

The limits of detection were estimated as the polyphenol concentration which gave a signal equal to $a+3 S_{a} / b$ (described in Section 2.5) [31]. As it can be seen in Table 3, the SPE $\mathrm{Oasis} \mathrm{HLB}_{\text {/ULPC- }}$ PDA methodology presented in general very low detection limits, ranging between 0.006 and $0.58 \mu \mathrm{g} \mathrm{mL}^{-1}$, for gallic acid and gentisic acid, respectively. The limits of quantification, estimated as the polyphenol concentration which gave a signal equal to $a+10 S_{a} / b$ [31], ranged from $0.019 \mu \mathrm{g} \mathrm{mL}^{-1}$ to $1.94 \mu \mathrm{g} \mathrm{mL}^{-1}$, again for gallic and gentisic acids, respectively. Comparing LOD and LOQ values obtained with those reported in literature for the phenolic compounds (Table 1 ) the values provided by this method are generally lower than the ones from the cited literature. The very low values for LOD and LOQ confirmed the high sensitivity of the proposed method for determination of bioactive phenolic metabolites in wines.

The precision of the method (Table 4) was evaluated based on its repeatability, which was ascertained by performing seven successive sample extractions from spiked red and white wines at three different concentration levels on the same day plus three extractions per day for 4 days (IP). The intra-day repeatability of peak areas, expressed by means of the percentage of relative standard deviation (\%RSD, $n=7$ ), was lower than $7 \%$ for red wines and $5 \%$ for white wines, with an average precision of $3 \pm 3 \%$, and $3 \pm 1 \%$, for red and white wines, respectively. The IP (inter-day repeatability, 4 days; $n=3$ ), was less than $10 \%$, in both wine types. For red wines the lowest IP value was obtained for myricetin (1.4\%) spiked at $3.5 \mu \mathrm{g} \mathrm{mL}^{-1}$, and the highest was obtained for gallic acid spiked at $0.5 \mu \mathrm{g} \mathrm{mL}^{-1}$ (10\%). For white wines the IP values ranging from $1.1 \%$ (myricetin, $3.5 \mu \mathrm{g} \mathrm{mL}^{-1}$ ) and $8.9 \%$ for kaempferol $\left(40.0 \mu \mathrm{g} \mathrm{mL}^{-1}\right.$ ).

Recovery studies were carried out to evaluate the accuracy of the method (Table 5). In order to study this parameter, red (PT) and white (LB) wines were fortified by addition of known 
Table 4

Precision evaluated as repeatability intra- and inter-day expressed as RSD (\%), obtained for PT red wine and TL white wine at three different concentration levels, low level (LL), middle level (ML) and high level (HL).

\begin{tabular}{|c|c|c|c|c|c|c|c|c|c|c|c|c|c|}
\hline & & \multirow{2}{*}{\multicolumn{3}{|c|}{$\begin{array}{l}\text { Intra-day }(n=7) \\
\text { Red wine }\end{array}$}} & \multicolumn{9}{|c|}{ Inter-day $(n=12)$} \\
\hline & & & & & \multicolumn{3}{|c|}{ White wine } & \multicolumn{3}{|c|}{ Red wine } & \multicolumn{3}{|c|}{ White wine } \\
\hline & & $\mathrm{LL}$ & ML & $\mathrm{HL}$ & LL & ML & $\mathrm{HL}$ & LL & ML & $\mathrm{HL}$ & LL & ML & $\overline{\mathrm{HL}}$ \\
\hline \multirow[t]{15}{*}{ Bioactive metabolites } & Gallic acid & 2.55 & 1.57 & 0.89 & 5.32 & 1.41 & 2.41 & 10.30 & 4.50 & 9.31 & 3.06 & 6.88 & 3.94 \\
\hline & Protocatechuic acid & 7.30 & 3.33 & 1.55 & 2.51 & 1.26 & 3.43 & 9.66 & 4.93 & 3.66 & 3.16 & 4.58 & 1.37 \\
\hline & (-)-Catechin & 2.85 & 1.42 & 0.34 & 2.42 & 1.77 & 2.82 & 2.02 & 3.90 & 4.10 & 2.00 & 1.23 & 4.36 \\
\hline & Gentisic acid & 4.75 & 2.30 & 3.82 & 1.57 & 1.61 & 1.30 & 9.13 & 6.93 & 2.18 & 1.94 & 4.02 & 4.55 \\
\hline & (-)-Epicatechin & 8.11 & 1.36 & 6.51 & 4.64 & 2.54 & 2.17 & 9.44 & 6.19 & 4.45 & 6.52 & 8.83 & 3.83 \\
\hline & Syringic acid & 3.44 & 2.89 & 3.01 & 5.21 & 2.44 & 1.48 & 7.10 & 2.36 & 1.76 & 3.89 & 6.39 & 2.21 \\
\hline & $p$-Coumaric acid & 1.62 & 3.10 & 2.55 & 3.20 & 1.65 & 4.14 & 1.54 & 8.66 & 8.16 & 2.86 & 6.15 & 2.26 \\
\hline & Ferulic acid & 5.02 & 1.52 & 1.70 & 4.17 & 1.27 & 6.24 & 2.21 & 5.02 & 5.74 & 3.68 & 5.39 & 8.51 \\
\hline & $m$-Coumaric acid & 2.51 & 1.53 & 2.91 & 2.80 & 1.24 & 1.89 & 2.69 & 6.18 & 1.13 & 7.25 & 5.80 & 4.06 \\
\hline & Rutin & 1.38 & 1.61 & 2.50 & 1.69 & 1.74 & 4.95 & 2.53 & 5.81 & 6.01 & 7.87 & 7.02 & 4.40 \\
\hline & Trans-resveratrol & 3.21 & 1.43 & 1.97 & 1.29 & 0.82 & 3.15 & 2.55 & 6.56 & 1.80 & 2.97 & 5.25 & 3.56 \\
\hline & Myricetin & 7.80 & 3.60 & 2.93 & 1.29 & 1.78 & 0.76 & 1.37 & 3.17 & 2.20 & 7.06 & 4.82 & 3.04 \\
\hline & Quercetin & 4.58 & 1.86 & 1.14 & 3.09 & 5.29 & 2.59 & 4.56 & 9.14 & 2.89 & 2.53 & 4.02 & 6.02 \\
\hline & Cinnamic acid & 5.55 & 2.77 & 2.43 & 1.13 & 1.58 & 5.54 & 512 & 5.68 & 4.36 & 4.92 & 5.65 & 5.92 \\
\hline & Kaempferol & 3.72 & 1.67 & 0.31 & 2.07 & 3.19 & 3.35 & 4.97 & 7.56 & 9.07 & 6.69 & 7.99 & 8.86 \\
\hline
\end{tabular}

amounts of polyphenols at three concentration levels, LL, ML and HL (Table 2). Each phenolic metabolite peak area versus the corresponding concentration was then interpolated from the linear regression equation. In general, good recoveries were obtained for the majority of polyphenolic compounds, except for rutin (red wines) and (-)-epicatechin (white wines) that showed the lowest recoveries $59 \pm 39 \%$ and $72 \pm 3 \%$, respectively, which can be attributed to their low polar structures. Nevertheless, the method accuracy was adequate for all target phenolics present in studied wines. For red wines the recoveries ranged from 57\% (rutin, HL - $32 \mu \mathrm{g} \mathrm{mL}^{-1}$ ) to $114 \%$ (quercetin, $\mathrm{ML}-10 \mu \mathrm{g} \mathrm{mL}^{-1}$ ), whereas in white wines the recoveries varied between $71 \%$ (gallic acid, LL $0.5 \mu \mathrm{g} \mathrm{mL}^{-1}$ ) and $12 \%$ (cinnamic acid, $\mathrm{LL}-3 \mu \mathrm{g} \mathrm{mL}^{-1}$ ) with an average recovery $\pm \operatorname{SD}(n=9)$ of $89 \pm 3 \%$ and $90 \pm 1 \%$, for red and white wines, respectively. The extraction efficiency was carried out at one concentration level, ML (Table 2) analysed in triplicate. The results are shown in Table 5 . As one can see, the results are satisfactory, being the extraction efficiencies higher than $77 \%$ (rutin), with an average $\pm \operatorname{SD}(n=3)$ of $89 \pm 7 \%$.

Taking together, the results obtained show that, besides being simple, fast and straightforward, the sample extraction using this SPE method with Oasis ${ }^{\mathrm{TM}}$ HLB cartridges presents a good reproducibility and accuracy [12].

\subsection{Determination of bioactive metabolites by $S P E_{\text {Oasis HLB }} / U H P L C-P D A$}

One of the main advantages of UHPLC technology is related to the possibility of attaining either ultra-fast or high resolving power separations. In order to demonstrate the applicability of the developed method, the SPE procedure was first applied to a mixture of polyphenols standards (Fig. 2a) and then to red and white wine samples (Fig. 2b). As shown in Fig. 2a, the separation of the standard mixture of 15 polyphenols compounds is very fast, being achieved within 5 min.

The chromatograms for white and red wines (Fig. 2b) showed quite different profiles and their complexity increases or decreases according to the wavelength (data not shown). The polyphenolic content in the wine samples analysed is represented in Table 6 . As can be easily observed, the polyphenols content is about six times more abundant in red wines than in white wines. This was widely described before in the literature [23].

Red wine from Azores (TLT) was by far the one that showed higher polyphenolic content considering the sum of the fifteen polyphenols tested (almost $240 \mu \mathrm{g} \mathrm{mL}^{-1}$ ), followed by Madeira and Canary Islands red wines, with polyphenolic compositions around 175 (TT) and $150 \mu \mathrm{g} \mathrm{mL}^{-1}$ (VT), respectively (see Table 5). In

Table 5

Validation parameters based on recoveries and extraction efficiency studies for SPE $\mathrm{Oasis}^{\circledR} \mathrm{HLB} / \mathrm{UPLC}$-PDA of bioactive metabolites in spiked red and white wines.

\begin{tabular}{|c|c|c|c|c|c|c|c|c|}
\hline & & \multicolumn{6}{|c|}{ Recovery (\%) } & \multirow{3}{*}{$\begin{array}{l}\text { Extraction efficiency (\%) } \\
\text { ML }^{\mathrm{b}}\end{array}$} \\
\hline & & \multicolumn{3}{|l|}{ Red wine } & \multicolumn{3}{|c|}{ White wine } & \\
\hline & & $\overline{L L^{a}}$ & $\mathrm{ML}^{\mathrm{a}}$ & $\mathrm{HL}^{\mathrm{a}}$ & $\overline{L L^{a}}$ & $M L^{\mathrm{a}}$ & $\mathrm{HL}^{\mathrm{a}}$ & \\
\hline \multirow[t]{15}{*}{ Bioactive metabolites } & Gallic acid & $80 \pm 7$ & $85 \pm 5$ & $84 \pm 8$ & $71 \pm 4$ & $67 \pm 5$ & $80 \pm 7$ & $87 \pm 9$ \\
\hline & Protocatechuic acid & $84 \pm 9$ & $103 \pm 8$ & $80 \pm 6$ & $84 \pm 8$ & $94 \pm 6$ & $79 \pm 6$ & $92 \pm 8$ \\
\hline & (-)-Catechin & $89 \pm 11$ & $85 \pm 7$ & $85 \pm 8$ & $113 \pm 9$ & $93 \pm 10$ & $89 \pm 5$ & $84 \pm 6$ \\
\hline & Gentisic acid & $81 \pm 13$ & $88 \pm 11$ & $82 \pm 9$ & $76 \pm 9$ & $86 \pm 7$ & $92 \pm 10$ & $85 \pm 3$ \\
\hline & (-)-Epicatechin & $95 \pm 10$ & $87 \pm 9$ & $80 \pm 6$ & $70 \pm 4$ & $72 \pm 5$ & $75 \pm 4$ & $80 \pm 5$ \\
\hline & Syringic acid & $84 \pm 9$ & $106 \pm 4$ & $92 \pm 8$ & $97 \pm 5$ & $95 \pm 5$ & $91 \pm 7$ & $91 \pm 7$ \\
\hline & p-Coumaric acid & $77 \pm 8$ & $90 \pm 8$ & $83 \pm 8$ & $103 \pm 9$ & $94 \pm 3$ & $97 \pm 6$ & $85 \pm 6$ \\
\hline & Ferulic acid & $95 \pm 10$ & $98 \pm 6$ & $82 \pm 9$ & $107 \pm 3$ & $98 \pm 4$ & $96 \pm 9$ & $90 \pm 3$ \\
\hline & $m$-Coumaric acid & $80 \pm 4$ & $95 \pm 9$ & $89 \pm 4$ & $103 \pm 4$ & $104 \pm 3$ & $82 \pm 3$ & $96 \pm 6$ \\
\hline & Rutin & $59 \pm 7$ & $63 \pm 5$ & $57 \pm 4$ & $74 \pm 4$ & $76 \pm 8$ & $79 \pm 6$ & $77 \pm 5$ \\
\hline & Trans-resveratrol & $105 \pm 7$ & $101 \pm 7$ & $100 \pm 5$ & $86 . \pm 7$ & $99 \pm 6$ & $97 \pm 6$ & $93 \pm 5$ \\
\hline & Myricetin & $85 \pm 8$ & $90 \pm 4$ & $111 \pm 5$ & $99 \pm 5$ & $92 \pm 3$ & $89 \pm 1$ & $90 \pm 7$ \\
\hline & Quercetin & $104 \pm 9$ & $114 \pm 6$ & $102 \pm 6$ & $89 \pm 5$ & $84 \pm 2$ & $78 \pm 4$ & $94 \pm 6$ \\
\hline & Cinnamic acid & $98 \pm 7$ & $96 \pm 6$ & $108 \pm 8$ & $116 \pm 3$ & $97 \pm 8$ & $101 \pm 5$ & $96 \pm 3$ \\
\hline & Kaempferol & $82 \pm 7$ & $81 \pm 5$ & $76 \pm 8$ & $89 \pm 4$ & $99 \pm 8$ & $102 \pm 3$ & $87 \pm 3$ \\
\hline
\end{tabular}

\footnotetext{
a $n=3$; average \pm RSD\%.
}

b $n=6$; average $\pm \mathrm{RSD} \%$. 

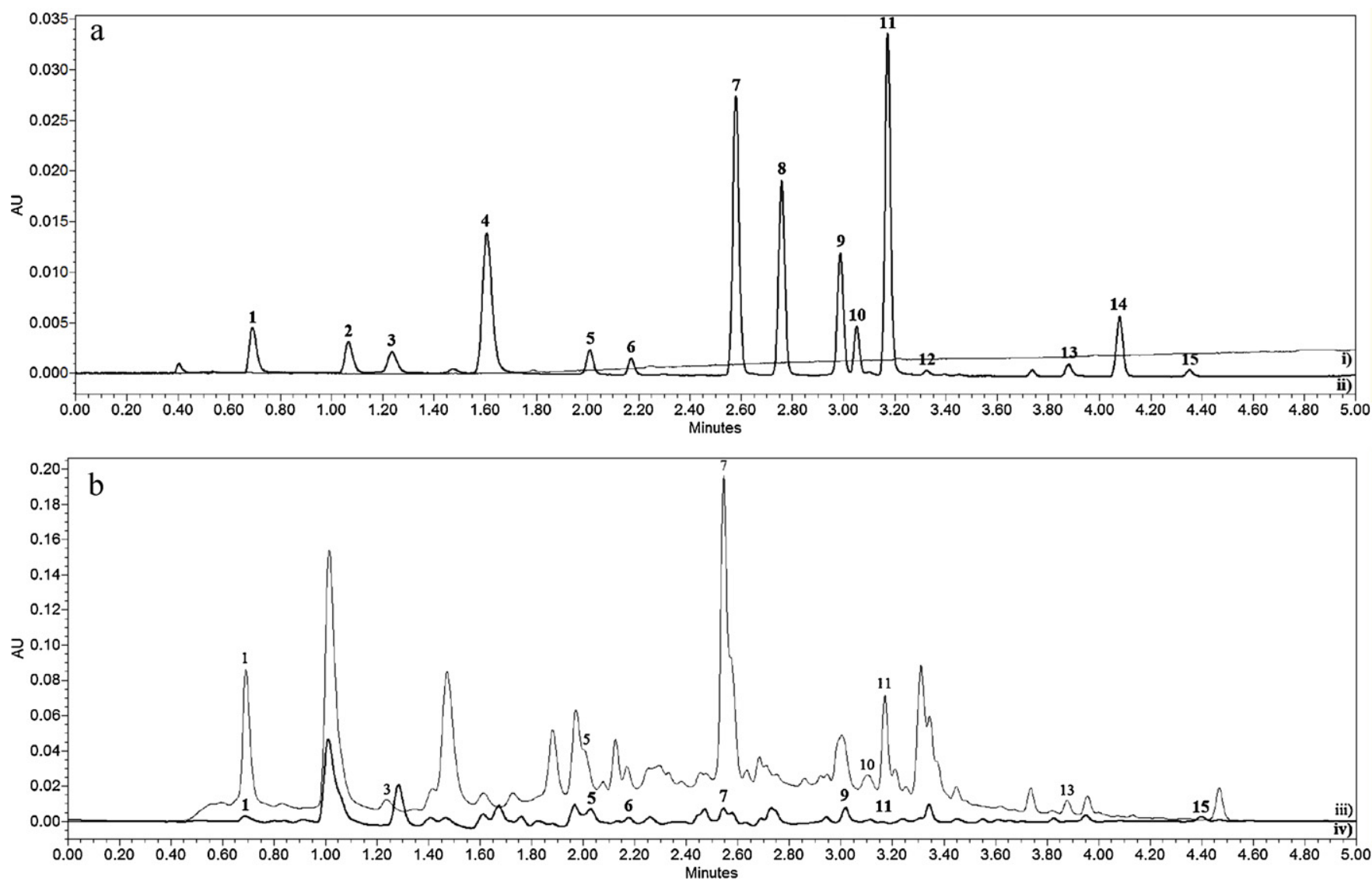

Fig. 2. (a) Chromatogram of (i) extractant solvent, in order to test the method selectivity; and (ii) a standard mixture of polyphenols; (b) UHPLC-PDA chromatogram of (iii) a red wine; and (iv) a white wine; using absorbance detection at $307 \mathrm{~nm}$. Individual retention times and peak identification of the polyphenols are presented in Table 1.

previous works where wine polyphenols composition from Azores Islands was compared with wines from other regions of Portugal, this same result was observed [26]. In white wines, the polyphenolic content is significantly lower, varying from $14 \mu \mathrm{g} \mathrm{mL}^{-1}$ in the $\mathrm{RBB}$, Madeira Island wine, up to $45 \mu \mathrm{g} \mathrm{mL}^{-1}$ in the Canary Island VGB wine. This fact makes white wines less prone to be effective in health protection against oxidative damage as the protective effects associated to moderate wine consumption have been attributed to their content in polyphenols [10,27]. In fact, Fuhrman and collaborators have shown that it was possible to have white wine with antioxidant characteristics similar to those of red wine just by increasing its polyphenols content, what could be easily obtained by increasing the extraction of grape skin polyphenols during the maceration process [28].

Table 6

Concentration $^{\mathrm{a}}$ of bioactive metabolites found in red and white wines assayed through proposed SPE Oasis HLB $/ U H P L C-P D A_{\text {method. }}$

\begin{tabular}{|c|c|c|c|c|c|c|c|c|c|c|}
\hline & \multirow[b]{2}{*}{ Sample identification } & \multicolumn{4}{|l|}{ Red wine } & \multicolumn{5}{|l|}{ White wine } \\
\hline & & VT & TLT & TT & PT & LB & EB & SB & RBB & VGB \\
\hline & Sample origin & $\mathrm{CAN}^{\mathrm{b}}$ & $\mathrm{AZO}^{\mathrm{b}}$ & $\mathrm{MAD}^{\mathrm{b}}$ & MAD & MAD & MAD & MAD & MAD & CAN \\
\hline \multirow[t]{13}{*}{ Bioactive metabolites } & Gallic acid & $2.1 \pm 1$ & $2.6 \pm 7$ & $4.0 \pm 5$ & $2.4 \pm 6$ & $0.2 \pm 10$ & $0.3 \pm 16$ & $0.4 \pm 10$ & $0.2 \pm 10$ & $0.2 \pm 3$ \\
\hline & Protocatechuic acid & $10 \pm 0.2$ & $6.9 \pm 2.3$ & & & & & $4.3 \pm 3$ & & \\
\hline & (-)-Catechin & $7.8 \pm 11$ & $51.1 \pm 6$ & $30.4 \pm 18$ & $377 \pm 8$ & & $1.2 \pm 16$ & & $1.9 \pm 4$ & $0.9 \pm 4$ \\
\hline & $\begin{array}{l}\text { Gentisic acid } \\
(-) \text {-Epicatechin }\end{array}$ & $95.8 \pm 2$ & $147.2 \pm 3$ & 123. $8 \pm 7$ & $19.9 \pm 2$ & $15.9 \pm 2$ & $14.9 \pm 2$ & $12.7 \pm 3$ & $9.8 \pm 5$ & $36.9 \pm 0.3$ \\
\hline & Syringic acid & $8.9 \pm 0.5$ & & $7.9 \pm 6$ & & $0.8 \pm 1$ & $0.7 \pm 3$ & $0.8 \pm 5$ & $0.3 \pm 3$ & $1.7 \pm 1$ \\
\hline & $\begin{array}{l}p \text {-Coumaric acid } \\
\text { Ferulic acid }\end{array}$ & $9.4 \pm 0.9$ & & & $7.1 \pm 4$ & $2.9 \pm 3$ & $2.2 \pm 2$ & $1.8 \pm 4$ & $2.8 \pm 2$ & $2.1 \pm 1$ \\
\hline & $m$-Coumaric acid & & & & & & $0.2 \pm 4$ & & & $0.1 \pm 3$ \\
\hline & Rutin & & $19.4 \pm 0.4$ & $8.4 \pm 10$ & $11.6 \pm 1$ & & & & & \\
\hline & Trans-resveratrol & & $6.5 \pm 6$ & & $5.1 \pm 9$ & & & & & $2.4 \pm 8$ \\
\hline & Myricetin & $9.7 \pm 2$ & & & & & & & & \\
\hline & Quercetin & & $5.4 \pm 6$ & & $2.1 \pm 9$ & & & $2.2 \pm 4$ & & \\
\hline & Cinnamic acid & & $0.8 \pm 2$ & & & & & & & \\
\hline & Kaempferol & $2.7 \pm 9$ & & & & & & & & $1.1 \pm 0$ \\
\hline
\end{tabular}

a The content of each of the fifteen polyphenols analysed in the wine samples tested is the mean of three replicates \pm RSD and indicated as $\mu g$ mL $^{-1}$. The gray-shadow boxes refer to polyphenols that were not detected in the respective wine sample.

b CAN (Canary Island), AZO (Azores) and MAD (Madeira) indicated the geographic origin of the wine samples. 
Regarding to the individual polyphenols, (-)-epicatechin is the most abundant polyphenol in all wines studied, being responsible for more than half of their phenolic composition. The second most abundant polyphenol is (-)-catechin, although it is not present in EB and VGB white wines. These two polyphenols have being extensively shown to have several health benefits, namely in the cardiovascular and neurodegenerative protection [32,33]. Gallic acid, also often reported in wine composition [34,35], was identified in all wine samples, while syringic and $p$-coumaric acid seems to be more specific to white wines. In the same way, $m$-coumaric acid was only identified in white wines, while rutin was only detected in red wines. Myricetin (in VT red wine) and kaempferol (in VGB white wine and VT red wine) were detected only in Canary Island wines. Gentisic and ferulic acids were not detected in any of the wine samples analysed and cinnamic acid was only identified at very low amounts in the Azores Island red wine TLT. Trans-resveratrol, an important bioactive polyphenols shown to have anti-mutagen and anti-fungal properties [13], usually present in red wines was identified in Azores (TLT $-6.50 \pm 0.06 \mu \mathrm{g} \mathrm{mL}^{-1}$ ) and Madeira (PT $-5.12 \pm 0.09 \mu \mathrm{g} \mathrm{mL}^{-1}$ ) red wines, but not in the Canary Island red wine (VT). Curiously it was identified in one of the white wines tested (VGB wine from Canary Island). Our data about trans-resveratrol are in agreement with the results from Baptista et al. $[26,35]$ that found amounts of this compound in the range of $0.63-5.21 \mathrm{mg} \mathrm{L}^{-1}$ in other Portuguese red wines, including one from Azores Island.

These results confirmed that wine polyphenolic composition is very heterogenic, being dependent of diverse factors, namely local climate and vinification conditions that are quite different among the wine samples used in this work.

\section{Conclusions}

In the current study an ultra-fast and simple UHPLC-PDA methodology, using a 50-mm column (Acquity BEH C18) packed with $1.7-\mu \mathrm{m}$ particles, was developed and validated for the simultaneous separation and quantification of 15 bioactive polyphenols in red and white wines. The method was validated with respect to selectivity, linearity, LOD, LOQ accuracy, precision and extraction efficiency for each of the fifteen compounds studied. The validation has shown that the method is linear, and sensitive with recovery, and precision values within the accepted limits for validation of food analytical methods. After a careful selection of the eluent systems, it was demonstrated that the chromatographic separation of the polyphenols could be achieved in within five minutes with high resolution. This is about ten times faster separation than that traditional HPLC approach allows for the same purpose. The combination of the shorter running time with a smaller flow rate also reduced drastically the solvent consumption and thus is more environmental friendly and economical. In order to reduce the complexity of wine extract samples and optimize the recovery efficiency, a rapid procedure based on SPE using methanol and ethyl acetate as extraction solvents was employed prior to the UHPLC-PDA analysis. Its practical application in selected wines has also been demonstrated.

The methodology here presented is suitable and very useful for an unambiguous determination of bioactive metabolites in wines and for routine use in laboratory. Moreover, the validated approach focused on wine matrices could be extended to other type of samples namely fruits, vegetables and processed foods.

\section{Acknowledgements}

The authors thank the financial support of FEDER (Transnational Cooperation MAC 2007-2013 Program) through VinSaudeMAC project (MAC/1/M105) and to Portuguese Foundation for Science and Technology (FCT) through the MS Portuguese Networks (REDE/1508/RNEM/2005) and Pluriannual base funding (QUIMadeira-674).

\section{References}

[1] J.S. Câmara, M.A. Alves, J.C. Marques, Anal. Chim. Acta 555 (2006) 191.

[2] R. Lopez, M. Aznar, J. Cacho, V. Ferreira, J. Chromatogr. A 966 (2002) 166.

[3] V. Ferreira, R. López, J. Cacho, J. Sci. Food Agric. 80 (2000) 1659

[4] J.S. Câmara, P. Herbert, J.C. Marques, M.A. Alves, Anal. Chim. Acta 513 (2004) 203.

[5] V. Ferreira, N. Ortin, A. Escudero, R. Lopez, J. Cacho, J. Agric. Food Chem. 50 (2002) 4048

[6] J.S. Câmara, M.A. Alves, J.C. Marques, Talanta 68 (2006) 1512.

[7] M. Prodanov, I. Garrido, V. Vacas, R. Lebron-Aguilar, M. Duenas, C. GomezCordoves, B. Bartolome, Anal. Chim. Acta 609 (2008) 241.

[8] N. Gheldof, X.H. Wang, N.J. Engeseth, J. Agric. Food Chem. 50 (2002) 5870.

[9] V.B. Schini-Kerth, C. Auger, J.H. Kim, N. Etienne-Selloum, T. Chataigneau, Pflugers Arch 459 (2010) 853.

10] M.I. Covas, P. Gambert, M. Fito, R. de la Torre, Atherosclerosis 208 (2010) 297.

[11] M. Naczk, F. Shahidi, J. Chromatogr. A 1054 (2004) 95

[12] S. Perez-Magarino, M. Ortega-Heras, E. Cano-Mozo, J. Agric. Food Chem. 56 (2008) 11560.

[13] M. Schwarz, M.C. Rodriguez, D.A. Guillen, C.G. Barroso, J. Sep. Sci. 32 (2009) 1782.

[14] Z. Spacil, L. Novakova, P. Solich, Talanta 76 (2008) 189.

[15] L.A. Kartsova, A.V. Alekseeva, J. Anal. Chem. 63 (2008) 1024.

[16] E. Rijke, P. Out, W.M.A. Niessen, F. Ariese, C. Gooijer, U.A.Th. Brinkman, J. Chromatogr. A 1112 (2006) 31.

[17] H. Wang, G.J. Provan, K. Helliwell, Food Chem. 81 (2003) 307.

[18] M. Pelillo, M. Bonoli, B. Biguzzi, A. Bendini, T. Gallina Toschi, G. Lercker, Food Chem. 87 (2004) 465.

[19] V. Atanasova, H. Fulcrand, V. Cheynier, M. Moutounet, Anal. Chim. Acta 458 (2002) 15-27.

[20] J.X. Castillo-Sánchez, M.S. García-Falcón, J. Garrido, E. Martínez-Carballo, L.R Martins-Dias, X.C. Mejuto, Food Chem. 106 (2008) 18-26.

[21] Z. Kerem, B.A. Bravdo, O. Shoseyov, Y. Tugendhaft, J. Chromatogr. A 1052 (2004) 211.

[22] V. Pereira, J.S. Camara, J. Cacho, J.C. Marques, J. Sep. Sci. 33 (2010) 1204

[23] J. Gruz, O. Novák, M. Strnad, Food Chem. 111 (2008) 789.

[24] M.A. Rodríguez-Delgado, G. González-Hernández, J.E. Conde-González, J.P. Pérez-Trujillo, Food Chem. 78 (2002) 523-532.

[25] D. Guillarme, C. Casetta, C. Bicchi, Jean-Luc Veuthey, J. Chromatogr. A 1217 (2010) 6882.

[26] J.A.B. Baptista, J.F.d.P. Tavaresa, R.C.B. Carvalho, Food Res. Int. 34 (2001) 345.

[27] Y. Kuroda, Y. Hara, Mutat. Res. 436 (1999) 69.

[28] B. Fuhrman, N. Volkova, A. Suraski, M. Aviram, J. Agric. Food Chem. 49 (2001) 3164.

[29] L. Nováková, Spacil Zdenek, M. Seifrtova, L. Opletal, P. Solich, Talanta 80 (2010) 1970.

[30] A.A. Bertelli, D.K. Das, J. Cardiovasc. Pharmacol. 54 (2009) 468

[31] J.N. Miller, J.C. Milller, Statistics and Chemometrics for Analytical Chemistry, Pearson Education, Harlow, UK, 2000.

[32] H.J. Heo, C.Y. Lee, J. Agric. Food Chem. 53 (2005) 1445.

[33] H. Schroeter, C. Heiss, J. Balzer, P. Kleinbongard, C.L. Keen, N.K. Hollenberg, H. Sies, C. Kwik-Uribe, H.H. Schmitz, M. Kelm, Proc. Natl. Acad. Sci. U.S.A. 103 (2006) 1024.

[34] J. González-Rodríguez, P. Pérez-Juan, M.D. Luque de Castro, Talanta 56 (2002) 53.

[35] N. Paixao, V. Pereira, J.C. Marques, J.S. Camara, J. Sep. Sci. 31 (2008) 2189. 